\title{
Assessment of Chronic Pain associated with Prolonged Standing and Effectiveness of Stretching Exercise on it among Security Personnel Working in an Educational Campus in Bhubaneswar
}

\section{Subhasri Subhadarsini ${ }^{1}$, Lisa Sarangi ${ }^{2}$, Subhasish Dwari ${ }^{3}$}

${ }^{1}$ Intern, $\mathrm{Hi}$ Tech Medical College and Hospital, Bhubaneswar; ${ }^{2}$ Professor, Department of Community Medicine, $\mathrm{Hi}$ Tech Medical College and Hospital, Bhubaneswar; ${ }^{3}$ Intern, Institute of Medical Sciences and SUM Hospital, Bhubaneswar, Odisha.

\begin{tabular}{|c|c|c|c|c|c|c|c|c|}
\hline Abstract & Introduction & Methodology & Results & Conclusion & References & Citation & \multicolumn{2}{|c|}{ Tables / Figures } \\
\hline \multicolumn{9}{|c|}{ Corresponding Author } \\
\hline \multicolumn{8}{|c|}{$\begin{array}{l}\text { Dr Lisa Sarangi, Professor, Department of Community Medicine, Hi-Tech Medical College and } \\
\text { Hospital, Bhubaneswar, Pandara, Rasulgarh, Bhubaneswar 751025, Odisha. } \\
\text { E Mail ID: sarangilisa@gmail.com }\end{array}$} & 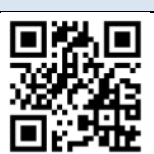 \\
\hline
\end{tabular}

\section{Citation}

Subhadarsini S, Sarangi L, Dwari S. Assessment of Chronic Pain associated with Prolonged Standing and Effectiveness of Stretching Exercise on it among Security Personnel Working in an Educational Campus in Bhubaneswar. Indian J Comm Health. 2021;33(1):103-108. https://doi.org/10.47203/IJCH.2021.v33i01.014

Source of Funding: Nil Conflict of Interest: None declared

\section{Article Cycle}

Received: 01/02/2021; Revision: 13/02/2021; Accepted: 05/03/2021; Published: 31/03/2021

This work is licensed under a Creative Commons Attribution 4.0 International License.

\section{Abstract}

Introduction: Prolonged standing is defined as a standing working posture for over $50 \%$ of total working hours during a full work shift. Chronic pain is defined as any pain lasting for more than 12 weeks. Standing effectively reduces the blood supply to the muscles and this inefficient blood flow accelerates the onset of fatigue and causes pain in the muscles. Some research has shown that exercise is an essential aspect in the treatment of chronic pain and gradually over time help those with pain. Significant increase in fitness and pain tolerance was seen in an exercise group in a study. Objectives: To assess the prevalence of chronic pain associated with prolonged standing, to determine the risk factors, to find out the effectiveness of stretching exercise and to suggest remedial measures to the security personnel. Materials and Method: Type of study: Interventional, Study design: Quasi experimental study Study Area: Educational group of institutions, Health Park, Bhubaneswar. Study population: Security personnel, Sample size:74 Sampling: Universal Sampling; Selection Criteria: Who is willing to give written consent and Work experience of 1 year. Study Period: August - October 2019 Study Instruments: Pre-tested, pre-designed questionnaire and standard Visual Pain Scale. Methodology: After obtaining IEC approval ,a pre-tested, predesigned questionnaire with a visual pain scale was used to obtain information about pain. Daily stretching exercises was performed. Statistical Analysis: Percentage, Chi-square, Mean,(ANOVA) and binary logistic regression. Result:28 had Chronic Back Pain that accounted to 37.83\%.A statistical significant association between years of service and back Pain (Chi square 6.653, $p=0.010$ ). On Binary logistic regression, Years of service (OR $1.1675, p 1.1675$ ) and Distance travelled (OR1.0699, $p$ 0.0489) had positive corelation. Significant difference in proportion in Extension positive test. Conclusion: Prolonged standing can lead to LBP and significant reduction in pain after intervention.

\section{Keywords}

Chronic Pain; Security Personnel; Exercise 


\section{Introduction}

Security guards working in an organisation face physical as well as psychological stress due to the tedious work involved in their job. Based on literature $(1,2)$ prolonged standing is defined as a standing working posture for over $50 \%$ of total working hours during a full work shift.

They are required to stand for long periods of time without being able to walk or sit during their work shift. They spend large fractions of their working time standing without the ability to sit down. Standing effectively reduces the blood supply to the muscles and this inefficient blood flow accelerates the onset of fatigue and causes pain in the muscles. Chronic pain is defined as any pain lasting for more than 12 weeks.(3) Generally while standing and walking, the increased pressure on spine can make the lower back muscles tightened leading to pain. Some common causes of pain include sprains, strains, spinal stenosis and degenerative disc diseases.(4)

Low back pain is a common clinical problem and a significant socioeconomic problem. Although the lifetime prevalence of back pain is $60-80 \%$, (5) little is known of its pathophysiology. Clinically, the natural course of low back pain is usually favorable; acute low back pain frequently disappears within one to two weeks. In some cases, however, acute low back pain becomes chronic and quite difficult to treat and has a major socioeconomic impact. Any of the spinal structures, including intervertebral discs, facet joints, vertebral bodies, ligaments, or muscles could be an origin of back pain, which is, unfortunately, quite difficult to determine. (6) In those cases in which the origin of back pain cannot be determined, the diagnosis given is nonspecific low back pain. (6)

Some research has shown that exercise is an essential aspect in the treatment of chronic pain and gradually over time help those with pain engaged more in activities of daily living. Significant increase in fitness and pain tolerance was seen in an exercise group in a study by Zones MD et al.(7)

The topic for the current study has been less researched and also very less literature is available to find any direct association between exercise and chronic pain. This study will therefore help to find any statistical association between these two variables.

\section{Aims \& Objectives}

1. To assess the prevalence of chronic pain associated with prolonged standing.

2. To determine the risk factors leading to chronic back pain in security guards.

3. To find out the effectiveness of stretching exercise among symptomatic security personnel.

4. To suggest remedial measures to the security personnel to improve their working conditions.

\section{Material \& Methods}

Type of study: Interventional

Study design: Quasi experimental study

Study Area: Educational group of institutions, $\mathrm{Hi}$ tech Health Park, Bhubaneswar.

Study population: Security personnel working inside this educational group of institutions, Health Park, Bhubaneswar.

Sample size: All the security personnel working in the educational campus fulfilling the selection criteria were selected for the study. Out of 82 total number of security guards working in the campus, 2 did not wish to be part of the study, 1 underwent bypass surgery three months prior to the commencement of study, 2 were absent at the time of enrollment and 3 did not have a working experience of 1 year. Therefore, the total sample size was 74 .

Sampling: By Universal Sampling all the security guards were selected as study participants.

\section{Selection Criteria:}

1) Inclusion criteria-(A) Who agreed to be a part of the study and gave written consent. (B) At least a work experience of 1 year.

2) Exclusion criteria- (A) Diagnosed with severe spondyloarthropathy. (B) Any diagnosed systemic disease like chronic kidney disease, heart disease, pancreatic disease and other debilitating diseases.

Study Period: August - October 2019

Study Instruments: Pre-tested, pre-designed questionnaire, general health checkup, Stretching exercise as advised by Physiotherapist and standard Visual Pain Scale. (8)

Ethical Clearance: It was obtained from Institutional Ethics Committee (No. HMCH/IEC/ICMR/19-01 Dt:25/04/19) and permission was granted from Security Supervisor, $\mathrm{Hi}$ Tech Health Park, Bhubaneswar, prior to the commencement of study. Department of Physiotherapy, Health Park, Bhubaneswar was contacted to support the research 
for physical examination of study subjects at baseline and also for follow up and advising the relevant stretching exercises.

Procedure: After Institutional Ethics Committee (IEC) clearance was obtained, the above study commenced. An informed written consent was obtained from each participant who was eligible as per the selection criteria. The study was explained to the participants and an assurance was given that their names will not be made public under any circumstances and the result will be used only for research purpose. Data was collected using a predesigned and pretested questionnaire.

The Department of Physiotherapy, Health Park, Bhubaneswar was involved to examine and subsequently advise the study participants, along with demonstration, the relevant stretching exercises. The demographic details, clinical history as per the predesigned and pretested questionnaire was collected and relevant physical examination, like forward bending(flexion), backward bending(extension), Straight Leg Raising (SLR), Faber and Slump tests (9) were conducted to determine back pain at the commencement of study.

After this baseline analysis, the security personnel, who complained of chronic pain (>12 weeks), were instructed on standard stretching exercises by trained physiotherapist. The exercises (i.e intervention) were to be done for two minutes only, repeated four times daily, over a period of eight working hours till the follow up. The security guards were contacted two times daily, once at 9 A.M and another at 5 P.M, to ensure and motivate them to continue the exercises. Every two weeks, a detailed health check up was done for the security personnel with back pain.

Two follow up examinations were done at an interval of 14 days each. The same questionnaire was filled up except the demographic details.

At the end of the study period, data compilation, tabulation and Statistical analysis was done, using MS Excel and SPSS version 21, at the Department of Community Medicine, $\mathrm{Hi}$ Tech Medical College and Hospital, Bhubaneswar, Odisha.

Statistical Analysis: Statistical analysis was done using Percentage, Chi-square, Mean, $F$ test (ANOVA) and binary logistic regression. (10) $P$ value less than 0.05 was considered statistically significant.

Quality control: A standard Pain scale (8) was used in the study to assess the pain at baseline and at each follow up. A pilot study was also taken up before the actual study commenced to test the questionnaire and expert Professionals were involved for examining and providing intervention to the study participants.

\section{Results}

Out of 74 participants, 28 had Chronic Back Pain that accounted to $37.83 \%$. Only two $(2.7 \%)$ security guards were females and rest were males. (Table 1) As shown in the above (Table 2), Security guards who have worked for five or more years, the prevalence of pain is $52.77 \%$ in comparison to those who have work experience of less than five years $(23.68 \%)$ and this had a statistically significant association $(p=0.01)$. There was also prevalence of pain $(47.05 \%)$ inspite of availability of sitting arrangement in work place. On applying chi square test, the value of chi square was 5.932 and $p=0.015$ which showed a significant association. Lifting of heavy weights and use of soft soles was not associated significantly with CBP. The pain got aggravated in $43.13 \%$ participants during day time though this finding was statistically not significant.

(Table 3) On Binary logistic regression, it was found out that Years of service (OR 1.1675, p 1.1675) and Distance travelled (OR1.0699, p 0.0489) to commute to the work place was statistically significant with positive correlation, while presence of any "Sitting arrangement" was negatively correlated (OR 0.2368 , p 0.0197).

(Table 4) On Examination, out of $71.4 \%$ who had flexion test positive at the start of study, $57.14 \%$ and $42.85 \%$ had positive result in first and second follow up respectively and continued to remain flexion positive.

There was a significant difference in proportion(chi square $=9.219 ; \mathrm{df}=1 ; \mathrm{p}=0.002395)$ in Extension positive test at Baseline (57.14\%) and 1st Follow up after the intervention (stretching exercise) (17.85\%) while the difference in proportion between 1st F/U and 2 nd $F / U$ was not statistically significant (chi square $=1.4694 ; d f=1 ; p=0.225442$ ).

Rest other tests like Flexion, SLR, Slump and Faber Tests did not show statistically significant difference in proportion at baseline and the subsequent Follow ups.

(Table 5) The mean pain score(SD) was 3.68(2.26) at baseline analysis. But, after the intervention, which included stretching exercises, the mean pain score(SD) at 1st and 2 nd F/U reduced to 2.57 (1.32) and 2.43 (1.35). 
The $F$ value is 4.50205 . The $p$ value is 0.013997 . The result is significant at $p<0.05$

(Table 6) shows that the difference of means at baseline mean pain score and at 1st Follow up and 2nd Follow up are statistically significant. (F 4.50205, p 0.013997).

\section{Discussion}

This Quasi-experimental study was conducted on 74 security guards working in an Educational Campus in Bhubaneswar showed that $37.83 \%$ complained of Chronic Back Pain. In another study done by Thomas R. Waters, (11) $40 \%$ had low backpain during prolonged standing which is at par with the present study (37.83\%).

In the present study, a significant association was found between years of service and Back Pain which points to more musculoskeletal wear and tear with time particularly when the job involves prolonged standing. It was also seen in this study that there was a positive correlation between distance of travel and complaint of back pain which predisposes to low back pain.

An interesting finding was seen in this study, where sitting arrangements, despite being present in the workplace, showed a negative correlation (coefficient-1.4404, (Table 3)) between the variables and was also statistically significant. This suggests that the mere presence of chairs may not affect Pain as they may not be used by the security guards who have to stand for long periods of time. In a study done by Robertson et al (12), showed significant difference in pain who used sit stand workstations in a 15-day experimental study. Therefore, further research is needed to study its relationship in the present study scenario.

Based on 6 Randomized Control Trials done by Sahar et al (13), on effectiveness of insoles, they concluded that there was no strong evidence that insoles reduced or prevented back pain which is similar to the findings of this study which shows not significant association between soft soles use and Back pain.

Out of five tests which were applied to examine the study participants, "Extension (Backward Bending)' showed statistically significant difference at baseline and 1st and 2nd Follow up. This may be because of the interventional stretching exercise, advised to those with positive Extension test, was easier to perform at the workplace. Therefore, compliance to this exercise might have been more.

A study Thomas R. Waters (11) by showed highly significant decrease in visual analogue score after exercise $(p<0.007)$ which is similar to the current findings where the mean Pain score decreased after the intervention and was statistically significant ( $p=0.013997)$.

\section{Conclusion}

This study suggests that prolonged standing in the workplace leads to a number of negative health outcomes particularly low back pain. A significant reduction in the low back pain after implementation of intervention suggests routine exercise in those suffering from low back pain due to prolonged standing can be helpful. Larger Randomised Control Trials studies can be conclusive on the above results. Monitoring the physical health of security personnel who are involved with prolonged standing during the working hours will help the employers to know about their health condition. Cost- effective and easily implementable stretching exercises should be advised to the security personnel at the time of job entry and frequent periodic medical examinations should be conducted. Sit-Stand workstations should be used in all the work places which involves prolonged standing.

\section{Recommendation}

Exercise during working hours must be promoted among security guards as they are standing for prolonged periods of time. A sit stand station must also be available for them. The employers must look into this for better retention and less workdays lost.

\section{Limitation of the study}

As this study was conducted in a single educational campus, larger studies are required for conclusive evidence. However, the study participants were well represented and inference was drawn from it.

\section{Relevance of the study}

Study on security guards have been less researched, this population needs to be studied for various health problems. Prolonged standing hours leading to musculoskeletal disorders was one of the integral part of their health checkup towards achieving an overall physical health.

\section{Authors Contribution}

All the authors have contributed equally. 


\section{Acknowledgement}

We acknowledge ICMR for the STS Program of 2019. We also acknowledge Dept. Of Physiotherapy, $\mathrm{Hi}$ tech college of Physiotherapy

\section{References}

1. I.Halim , A.R.Omar, A.M.Saman and I.Othman,Assessment of muscle fatigue associated with prolonged standing in workplace,Safety and Health at Work (Shaw)(2012).

2. Tomei F, Baccolo TP, Tomao E, Palmi S, Rosati MV. Chronic venous disorders and occupation. Am J Ind Med. 1999;36(6):653-65. doi: 10.1002/(sici)10970274(199912)36:6<653::aid-ajim8>3.0.co;2-p. $\quad$ PMID: 10561686. [PubMed].

3. https://medlineplus.gov/magazine/issues/spring11/article s/pg5-6.html [last accessed on 20 feb 2021]

4. Maheswari J.Essential Orthopaedics Arthritis And Related Diseases.5th Edition.Mehta Publishers,2015.

5. Nachemson A. Epidemiology and the economics of low back pain. In: Herkowits H, Dvorak J, Bell G, Nordin M, Grob D, editors. The Lumbar Spine. 3rd edition. Philadelphia, $\mathrm{Pa}$, USA: Lippincott; 2004

6. Balagué $F$, Mannion AF, Pellisé $F$, Cedraschi $C$. Non-specific low back pain. Lancet. 2012;379(9814):482-91. doi: 10.1016/S0140-6736(11)60610-7. Epub 2011 Oct 6. PMID: 21982256. [PubMed].
[Assessment of Chronic Pain...] | Subhadarsini S et al

7. Jones MD, Booth J, Taylor JL, Barry BK. Aerobic training increases pain tolerance in healthy individuals. Med Sci Sports Exerc. 2014;46(8):1640-7. doi: 10.1249/MSS.0000000000000273. PMID: 24504426.[PubMed]

8. https://www.disabled-world.com/health/pain/scale.php [accessed on 20 Feb 2021].

9. Magee David J. Orthopedic Physical Assessment.5th Edition.SAUNDERS Elsevier, 2008.

10. Mahajan B.K. Methods in Biostatistics For Medical Students and research Workers.7th Edition. Jaypee Brothers,2010

11. Waters TR, Dick RB. Evidence of health risks associated with prolongedstanding at work and intervention effectiveness. Rehabil Nurs. 2015;40(3):148-65. doi: 10.1002/rnj.166. Epub $2014 \quad$ Jul 7. PMID: 25041875; PMCID:PMC4591921.[PubMed].

12. Robertson MM, Ciriello VM, Garabet AM. Office ergonomics training and a sit- stand workstation: effects on musculoskeletal and visual symptoms and performance of office workers. Appl Ergon. 2013;44(1):73-85. doi: 10.1016/j.apergo.2012.05.001. Epub 2012 Jun 22. PMID: 22727324.[PubMed]

13. Sahar T, Cohen MJ, Ne'eman V, Kandel L, Odebiyi DO, Lev I, Brezis $M$, Lahad A. Insoles for prevention and treatment of back pain. Cochrane Database Syst Rev. 2007;(4):CD005275.

10.1002/14651858.CD005275.pub2.

doi: 17943845.[PubMed].

\section{Tables}

TABLE 1 PREVALENCE OF CHRONIC BACK PAIN AMONG SECURITY GUARDS

\begin{tabular}{|c|c|c|}
\hline PAIN & NUMBER & PERCENT \\
\hline Present & 28 & 37.83 \\
\hline Absent & 46 & 62.16 \\
\hline Total & 74 & 100 \\
\hline
\end{tabular}

TABLE 2 ASSOCIATION OF RISK FACTORS WITH CHRONIC BACK PAIN

\begin{tabular}{|c|c|c|c|c|}
\hline YEARS OF SERVICE & PAIN PRESENT No.(\%) & PAIN ABSENT No. (\%) & TOTAL No. (\%) & Chi Square (P Value) \\
\hline$>=5$ & 19(52.77) & $17(47.22)$ & $36(100)$ & \\
\hline$<5$ & $9(23.68)$ & $29(76.31)$ & $38(100)$ & $6.653(0.01)$ \\
\hline TOTAL & $28(37.83)$ & $46(62.16)$ & 74(100) & \\
\hline \multicolumn{5}{|c|}{ SITTING ARRANGEMENT } \\
\hline PRESENT & $24(47.05)$ & $27(52.94)$ & $51(100)$ & \\
\hline ABSENT & $4(17.39)$ & 19(82.60) & $23(100)$ & $5.932(0.015)$ \\
\hline TOTAL & $28(37.83)$ & $46(62.16)$ & $74(100)$ & \\
\hline \multicolumn{5}{|c|}{ LIFTING HEAVY WEIGHT } \\
\hline PRESENT & $6(26.08)$ & 17(73.91) & $23(100)$ & \\
\hline ABSENT & $22(43.13)$ & $29(56.86)$ & $51(100)$ & $1.959(0.162)$ \\
\hline TOTAL & $28(37.83)$ & $46(62.16)$ & $74(100)$ & \\
\hline \multicolumn{5}{|l|}{ SOFT SOLES SHOE } \\
\hline USE & $23(45.09)$ & $28(54.90)$ & $51(100)$ & \\
\hline DOES NOT USE & $5(21.73)$ & $18(78.26)$ & $23(100)$ & $3.677(0.552)$ \\
\hline TOTAL & $28(37.83)$ & $46(62.16)$ & 74(100) & \\
\hline \multicolumn{5}{|c|}{ AGGRAVATES DURING DAY } \\
\hline YES & $22(43.13)$ & $29(56.86)$ & $51(100)$ & \\
\hline NO & $06(26.08)$ & 17(73.91) & $23(100)$ & $1.9591(0.162)$ \\
\hline TOTAL & $28(37.83)$ & $46(62.16)$ & $74(100)$ & \\
\hline
\end{tabular}




\begin{tabular}{|c|c|c|c|c|c|}
\hline Variable & Coefficient & Standard Error & $p$-value & Odds Ratio & $\begin{array}{l}\text { 95\% Confidence } \\
\text { Interval (LL,UL) }\end{array}$ \\
\hline Years of service & 0.1549 & 0.0426 & 0.0003 & 1.1675 & $(1.074,1.2692)$ \\
\hline Distance travelled to work place $(\mathrm{Km})$ & 0.0675 & 0.0343 & 0.0489 & 1.0699 & $(1.0003,1.1442)$ \\
\hline Sitting arrangement & -1.4404 & 0.6175 & 0.0197 & 0.2368 & $(0.0706,0.7945)$ \\
\hline Heavy weight Lifting & 0.7652 & 0.5527 & 0.1662 & 2.1494 & $(0.7276,6.3496)$ \\
\hline
\end{tabular}

\begin{tabular}{|c|c|c|c|c|}
\hline & Tests & Baseline(\%) & 1 st $\mathrm{f} / \mathrm{u}$ & $2 n d f / u$ \\
\hline \multirow{2}{*}{ FLEXION } & POSITIVE & 20(71.4) & $16(57.14)$ & $12(42.85)$ \\
\hline & NEGATIVE & $8(28.57)$ & $12(42.85)$ & $16(57.14)$ \\
\hline \multirow{2}{*}{ EXTENSION } & POSITIVE & $16(57.14)$ & $5(17.85)$ & $2(7.14)$ \\
\hline & NEGATIVE & $12(42.85)$ & $23(82.14)$ & $26(92.85)$ \\
\hline \multirow{2}{*}{ SLR } & POSITIVE & $26(92.85)$ & $22(78.57)$ & $20(71.42)$ \\
\hline & NEGATIVE & $2(7.14)$ & $6(21.42)$ & $8(28.57)$ \\
\hline \multirow{2}{*}{ SLUMP } & POSITIVE & $14(50)$ & $14(50)$ & $10(35.71)$ \\
\hline & NEGATIVE & $14(50)$ & $14(50)$ & $18(64.28)$ \\
\hline \multirow{2}{*}{ FABER } & POSITIVE & $18(64.28)$ & $18(64.28)$ & $14(50)$ \\
\hline & NEGATIVE & $10(35.71)$ & $10(35.71)$ & $14(50)$ \\
\hline
\end{tabular}

\section{TABLE 5 MEAN PAIN SCORE BEFORE AND AFTER INTERVENTION (STRETCHING EXERCISE)

\begin{tabular}{|l|l|l|l|}
\hline Exercise & BASELINE MEAN PAIN SCORE(S.D) & $1^{\text {ST }}$ F/U MEAN PAIN SCORE(S.D) & $2^{\text {ND }}$ F/U MEAN PAIN SCORE(S.D) \\
\hline $3.68(2.26)$ & $2.57(1.32)$ & $2.43(1.35)$ \\
\hline
\end{tabular}

\section{TABLE 6 F TEST RESULT BEFORE AND AFTER INTERVENTION (EXERCISE) BETWEEN MEANS OF PAIN} SCORE AT BASELINE AND 1ST AND 2ND FOLLOW UP

\begin{tabular}{|l|l|l|l|l|}
\hline Source & Sum of Squares & df & Mean Square & F value \\
\hline Between treatments & 26.2143 & 2 & 13.1017 & 4.50205 \\
\hline Within treatments & 235.8214 & 81 & 2.9114 & \\
\hline Total & 262.0357 & 83 & & \\
\hline
\end{tabular}

